\title{
HUMAN MACROPHAGES ARE SUSCEPTIBLE TO CORONAVIRUS OC43
}

\author{
Arlene R. Collins \\ Department of Microbiology \\ School of Medicine and Biomedical Sciences \\ State University of New York at Buffalo \\ Buffalo, New York 14214
}

\section{ABSTRACT}

Adherent adult and cord blood macrophages were infected with human coronavirus OC43 at a multiplicity of 1-1.5 and washed twice to remove unbound virus. Virus progeny was detected in the supernatant on day 1 and peaked at 2-3 days at an average titer of $5 \pm 3.9 \times 10^{6} \mathrm{pfu} / \mathrm{ml}$ from seven samples. Viral RNA was detected by nested set RT-PCR in infected macrophages incubated for $48 \mathrm{hr}$. Intracellular viral nucleocapsid was detected in $15 \%$ of the cells and surface staining for viral spike antigen was observed using monoclonal antibodies. Amplification of infectious virus and detection viral RNA and antigen synthesis in macrophages in vitro indicates susceptibility to OC43 virus.

\section{INTRODUCTION}

Human coronaviruses are the second most frequent viruses after the rhinoviruses, isolated from individuals with common colds. Two major serotypes, 229E and OC43 are found. Very little is known about the cytopathology of OC43 virus in the nasopharyngeal epithelium because of its fastidious growth requirements (McIntosh,1996). In human tracheal organ cultures, OC43 shows a slow patchy destruction of ciliated epithelial cells that is reflected in a loss of beating cilia. It is likely that this destructive effect has a role in the pathogenesis of disease caused by human coronaviruses. Beyond this however, there is little information concerning disease mechanisms (Tyrrell and Bynoe, 1965). OC43 causes a persistent infection in U87-MG glioblastoma cells (Collins, 1987). The purpose of this work is to determine the susceptibility of primary human monocytes/macrophages to infection with OC43. 


\section{MATERIALS AND METHODS}

\subsection{Cells and Viruses}

Primary monocyte/macrophage cells were isolated from six cord blood samples and one adult peripheral blood. Samples were collected in vacutainer tubes with EDTA (Becton Dickinson). The leucocyte layer was separated by gradient centrifugation at $800 \mathrm{xg}$ through Nycoprep solution (Accurate Chemical) and cultured in RPMI 1640 medium (GIBCO/BRL) with $10 \%$ fetal bovine serum (fbs) (Atlanta Biologicals), $2 \mathrm{mM}$ glutamine and $0.05 \mathrm{mg} / \mathrm{ml}$ Gentamycin. Nonadherent cells were removed during exchange with fresh medium. BAES-2B cells, derived from adenovirus transformed human bronchial epithelium, were grown and maintained in LHC-9 serum-free defined medium (Becker et al.,1993). After five to seven days in culture, cells were infected with a multiplicity of 1-1.5 pfu per cell in $25 \mathrm{~cm}^{2}$ flask containing $1-1.5 \times 10^{6}$ cells. After adsorption at $37^{\circ} \mathrm{C}$, for $1 \mathrm{hr}$, cells were washed twice with medium alone, and the first sample of medium was taken for virus assay. Samples were taken daily and stored at $-70^{\circ} \mathrm{C}$. Virus yield was determined by plaque assay on MRC- 5 human diploid lung cell monolayers (ViroMed, Minneapolis MN) and expressed as plaque forming units per milliliter (pfu/ml) (Collins, 1995).

\subsection{Detection of Viral RNA}

RNA was isolated from $1 \times 10^{6}$ infected and uninfected cells using PUREscript RNA isolation system (Gentra). For RT-PCR, the nested PCR assay of Myint et al. (1994) was used except that for first strand cDNA synthesis in which downstream primer 5'TGTGATTCTTCCAATTGGCC3' (Kamahora et al, 1989) was used.

\subsection{Immunocytochemistry}

Macrophages were placed in ice cold, phosphate buffered saline $0.1 \mathrm{M}, \mathrm{pH} 7.2$ (PBS) for 15 min followed by scraping and resuspension in fresh medium. Cells were seeded in $60 \mathrm{~mm}$ Petri dishes containing glass coverslips. After attachment, the cells were infected with virus at a multiplicity of 1-1.5. After five days, infected cells were washed twice in PBS, fixed in cold acetone for $10 \mathrm{~min}$, air dried and stained with monoclonal antibody $(\mathrm{mAb})$ 4B6.2 (1:500) to viral nucleocapsid antigen, followed by horse anti-mouse antibody conjugated to FITC (1:50,Vector, Burlingame CA).

For cell surface antigens, infected cells after washing in PBS, were incubated with rat mAb I16 to OC43 spike antigen (1:.25, J Vautherot, INRA, Juoy-en-Josas, France) or mAb B1-1G6 to $\beta 2$ microglobulin, light chain of HLA class I (Immunotech, 1:50), followed by biotin-conjugated goat anti-mouse IgG(1:40, Vector), then by avidin FITC (1:50, Vector). Cells were post-fixed in methanol/acetone 1:1 for $10 \mathrm{~min}$, visualized at $400 \mathrm{x}$ magnification in a Leitz Dialux20 UV fluorescence microscope and photographed using Kodak P3200 black and white film. The number of fluorescent cells was evaluated in 200-500 cells per culture.

\section{RESULTS}

Monocytes/macrophages recovered from healthy donor blood were infected with OC43 virus. Virus replication was monitored by plaque assay of the culture supernatant. In Table 1, the virus titers from monocyte/ macrophage cultures obtained from seven donors, 
Table 1. Susceptibility of human cord blood macrophage cultures to coronavirus $\mathrm{OC} 43$

\begin{tabular}{lcccc}
\hline & \multicolumn{4}{c}{ Virus titer, PFU/ml of supernatant medium on day } \\
\cline { 2 - 5 } Sample & $0^{\mathrm{c}}$ & 1 & 2 & 3 \\
\hline 214 & $1.2 \times 10^{2}$ & - & $1.8 \times 10^{7}$ & - \\
217 & $2.8 \times 10^{2}$ & $3.9 \times 10^{4}$ & $2.2 \times 10^{5}$ & $5.2 \times 10^{5}$ \\
218 & $2.2 \times 10^{2}$ & $4.5 \times 10^{4}$ & $1.2 \times 10^{6}$ & $5.7 \times 10^{5}$ \\
$226^{\mathrm{a}}$ & - & $1.0 \times 10^{6}$ & $1.5 \times 10^{6}$ & $3.0 \times 10^{6}$ \\
231 & - & $7.5 \times 10^{5}$ & $2.5 \times 10^{6}$ & $3.8 \times 10^{5}$ \\
239 & $1.6 \times 10^{2}$ & - & $3.2 \times 10^{6}$ & $2.0 \times 10^{6}$ \\
$241^{\mathrm{b}}$ & - & - & $6.3 \times 10^{6}$ & $1.5 \times 10^{5}$ \\
\hline${ }^{\mathrm{a}}$ Cells were infected at a multiplicity of 1.5; all others were infected at a multiplicity \\
of I. \\
b Adult peripheral blood monocytes; all the other cells are from cord blood. \\
${ }^{\mathrm{c}}$ Supernatant medium was sampled after washing the monolayer twice to remove un- \\
bound virus.
\end{tabular}

$\begin{array}{llllllllll}1 & 2 & 3 & 4 & 5 & 6 & 7 & 8 & 9 & 10\end{array}$

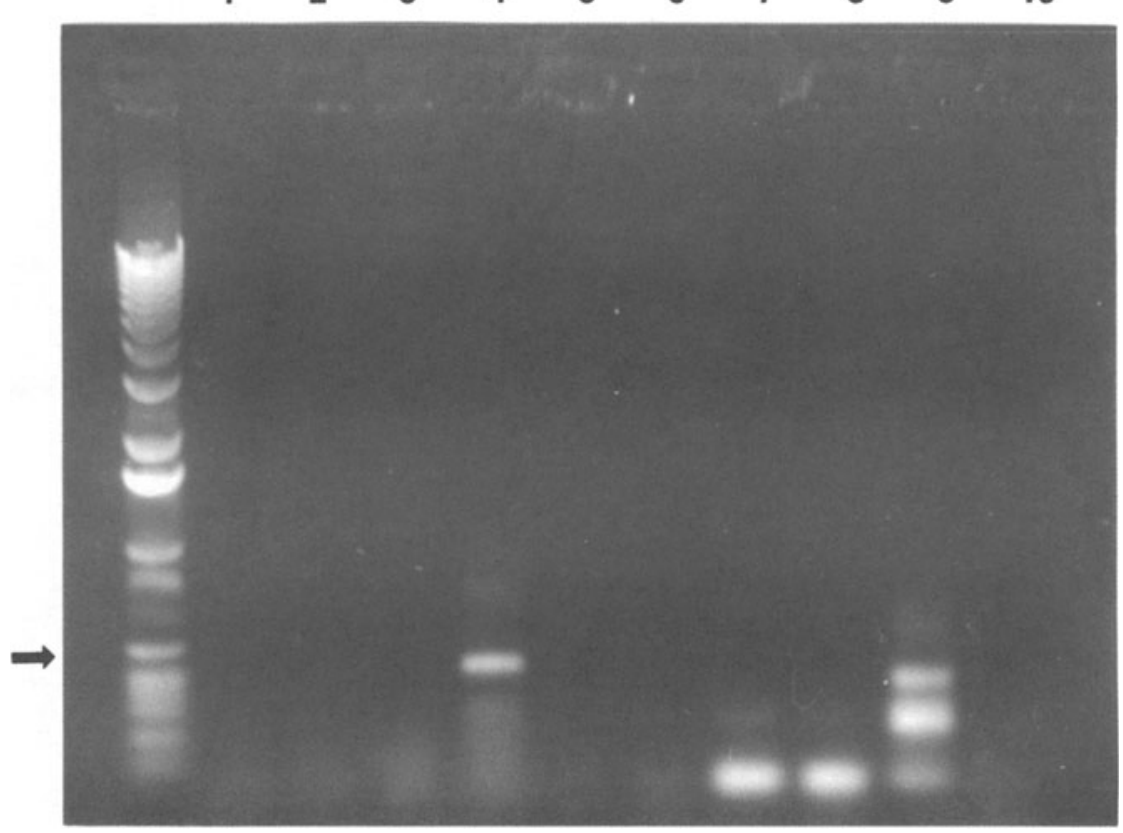

Figure 1. Agarose gel electrophoresis of products from RT-PCR. On left, molecular size markers, arrow shows $500 \mathrm{bp}$. Lanes 1 and 5, first round products. Lanes 6 and 10, second round products. Lanes 1 and 6 uninfected macrophages. Lanes 2 and 7 infected macrophages. Lanes 3 and 8 infected BAES-2B cells Lanes 4 and 9 infected MRC- 5 cells. Lanes 5 and 10, uninfected MRC- 5 cells. 
six cord blood and one adults are shown. After $48 \mathrm{hr}$, an average of $5 \pm 3.9 \times 10^{6}$ infectious virus particles per $\mathrm{ml}$ of supernatant medium was consistently recovered.

RT-PCR was applied to monocyte/macrophage cells from the eighth donor cord blood after infection with OC43 virus and incubation for $48 \mathrm{hr}$. Similarly infected MRC-5 and BAES-2B cells and uninfected macrophages were used as controls. Figure 1 shows that RNA from infected MRC-5 cells was positive for coronavirus in the first PCR cycle and gave a product of the expected size, 450 base pairs (bp). Macrophages and BAES-2B cells were positive after the second cycle. The product was a 100 base pair fragment, as expected. The second amplification from MRC-5 cells gave two additional products, one of $450 \mathrm{bp}$, identical to that seen in the first round and another of $300 \mathrm{bp}$ which was observed previously (Myint et al. 1994).

After immunocytochemical staining, microscopic observation and counting showed that $15 \%$ of macrophages that stained positive with anti-nucleocapsid $\mathrm{mAb}$ on day five. Nucleocapsid staining was a punctate or granular cytoplasmic fluorescence, Figure 2A. Macrophages stained with secondary antibody alone did not give this appearance, Figure 2B. Viral spike antigen on the surface of infected monocytes was also detected (Figure $2 \mathrm{C}$ ). Unstained cells lacking spike antigen were also visible. Figure 2D shows that cells stained fairly uniformly positive for surface $\beta 2 \mathrm{~m}$. Presence of surface staining for OC 43 spike corroborated the intracytoplasmic staining for nucleocapsid antigen.
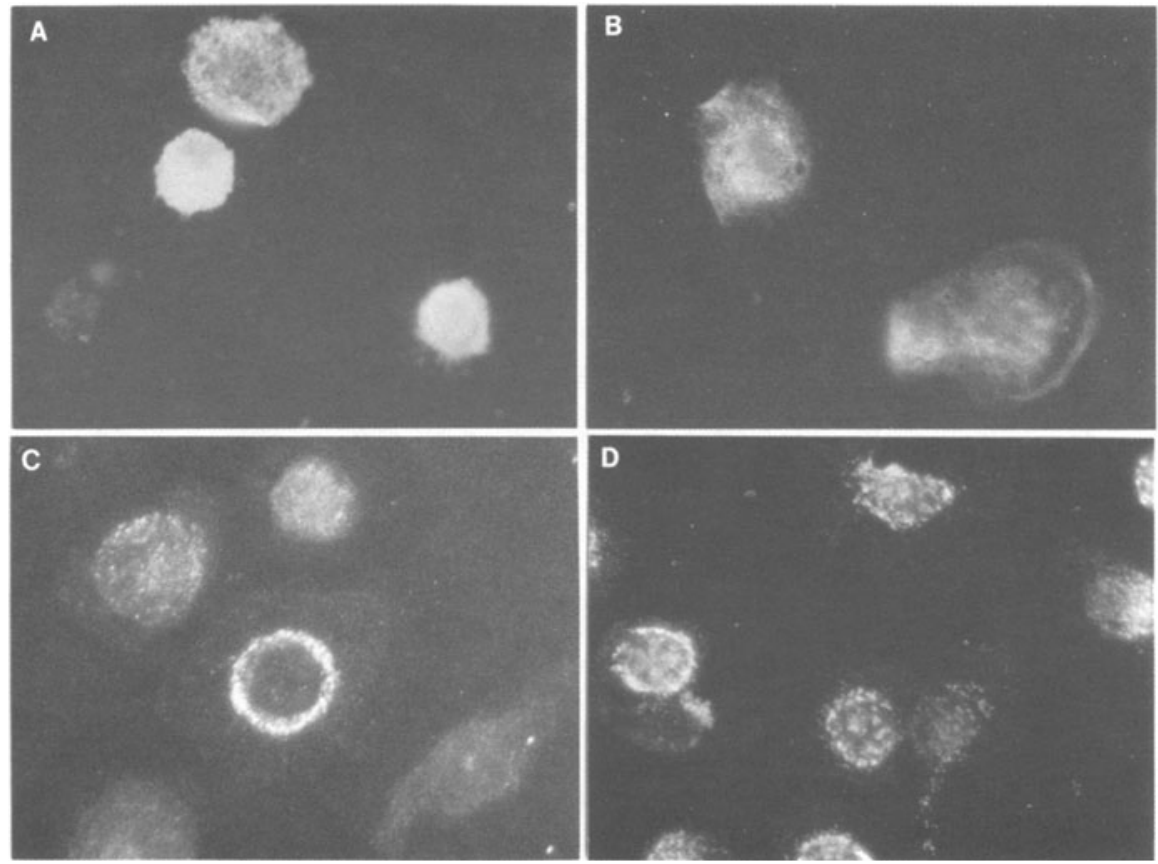

Figure 2. Immunofluorescent staining of OC43 infected monocyte/macrophages. A. day five after infection, stained with anti-nucleocapsid mAb. Cytoplasmic granules are stained. B. Same as A, except stained with secondary antibody, horse anti-mouse IgG ( $\mathrm{H}$ and $\mathrm{L}$ ). C. day three after infection, stained as unfixed cells with antispike mab. D. Same as $C$, except stained with anti- $\beta 2 \mathrm{~m}$ mAb. Magnification $400 \mathrm{x}$. 


\section{DISCUSSION}

Plaque assay, RT-PCR and immunocytology strongly indicate that OC43 virus replicated in human monocyte/macrophage cells in vitro. The estimated number of cells with intracytoplasmic nucleocapsid antigen was 15\%, suggesting that a subpopulation of macrophages was infected. Susceptibility of a subset of macrophages to respiratory syncytial virus has also been demonstrated (Midulla et al., 1989).

OC43 causes the common cold with cough and hyperemia, and reinfection is common. OC43 also can infect neurons (Collins, 1995; Bonavia et al., 1996) and viral RNA was found in the brain of multiple sclerosis patients (Talbot, 1997). These are reasons to look further into the pathogenesis of OC43 virus.

\section{REFERENCES}

Becker, S., Koren, H.S., and Henke, D.C., 1993, Interleukin-8 expression in normal nasal epithlelium and its modualtion by infection with respiratory syncytial virus and cytokines tumor necrosis factor, interleukin-1 and interleukin-6, Amer. J. Resp. Cell. Mol. Biol. 8: 20-27.

Bonavia, A., Arbour, N., Yong, V.W., Talbot, P.J., 1997, Infection of primary cultures ofhuman neural cells by human coronavirus 229E and OC43, J. Virol. 71: 800-6.

Collins, A.R., and Sorenson, O., 1986, Regulation of viral persistence in human glioblastoma and rhabdosarcoma cells infected with coronavirus OC43, Microb. Path. 1: 573-582.

Collins, A.R., 1995, Interferon gamma potentiates human coronavirus infection of neuronal cells by modulation of HLA class I, Immunol. Invest. 24: 977-986.

Kamahora, T., Soe, L.H., and Lai, M.M.C., 1989, Sequence analysis of nucleocapsid gene and leader RNA of human coronavirus OC43, Virus Res. 12: 1-9.

Mc Intosh, K., 1996, Coronaviruses, in: Fundamental Virology, (B.N.Fields, D.M. Knipe, R.M. Chanok, M. S. Hirsch, J.L. Melnick, T.P. Monath, B. Roizman, eds.), Raven, Philadelphia, pp.1093-1103.

Midulla, F., Huang, Y.T., and Gilbert, I.A., 1989, Respiratory syncytial virus infection of human cord and adult blood monocytes and alveolar macrophages, Amer Rev. Res. Dis. 140: 771-777.

Myint, S., Johnson,S., Sanderson,G., and Simpson, H., 1994, Evaluation of nested polymerase chain methods for the detection of human coronavirus $229 \mathrm{E}$ and OC43, Molec. Cell. Probes 8:357-361.

Talbot, P.J. Cote G., Arbour, N., 1997, Human coronavirus OC43 and 229E persistence in neural cell cultures and human brains, $A d v$. Exp. Med. Biol. In press.

Tyrrell, D.A.J., and Bynoe, M.L., 1965, Cultivation of a novel type of common cold virus in organ culture, $B r$. Med. J. 1: $1467-1470$. 